\title{
SSTS (ZLALVISOQ) IS A VIABLE ALTERNATIVE TO REGIONAL ANESTHESIA FOR POST OPERATIVE PAIN MANAGEMENT IN THORACIC SURGERY
}

F. Costa', F.E. Agrò', A. Valenzano', M. Martuscelli', E. Di Sabatino', F. Riccone', F. Longo², P. Crucitti², G. Pascarella', R.Del Buonol - 'Campus Bio Medico University Hospital, Unit of Anesthesia- Intensive Care and Pain Management, Rome, Italy. ${ }^{2}$ Campus Bio Medico University Hospital, Unit of Thoracic Surgery, Rome, Italy.

Background and Aims: Pain after thoracic surgery is severe [I] and could affect pulmonary function by reducing deep breathing and coughing ability, resulting in reduced clearance of secretions, and pneumonia [I]. Analgesia with Sufentanil Sublingual Tablet System (Zalviso ${ }^{\circledR}$ ) is effective for pain control after abdominal [2] and orthopedic surgery [3]. We experienced SSTS for postoperative pain management after thoracic surgery.

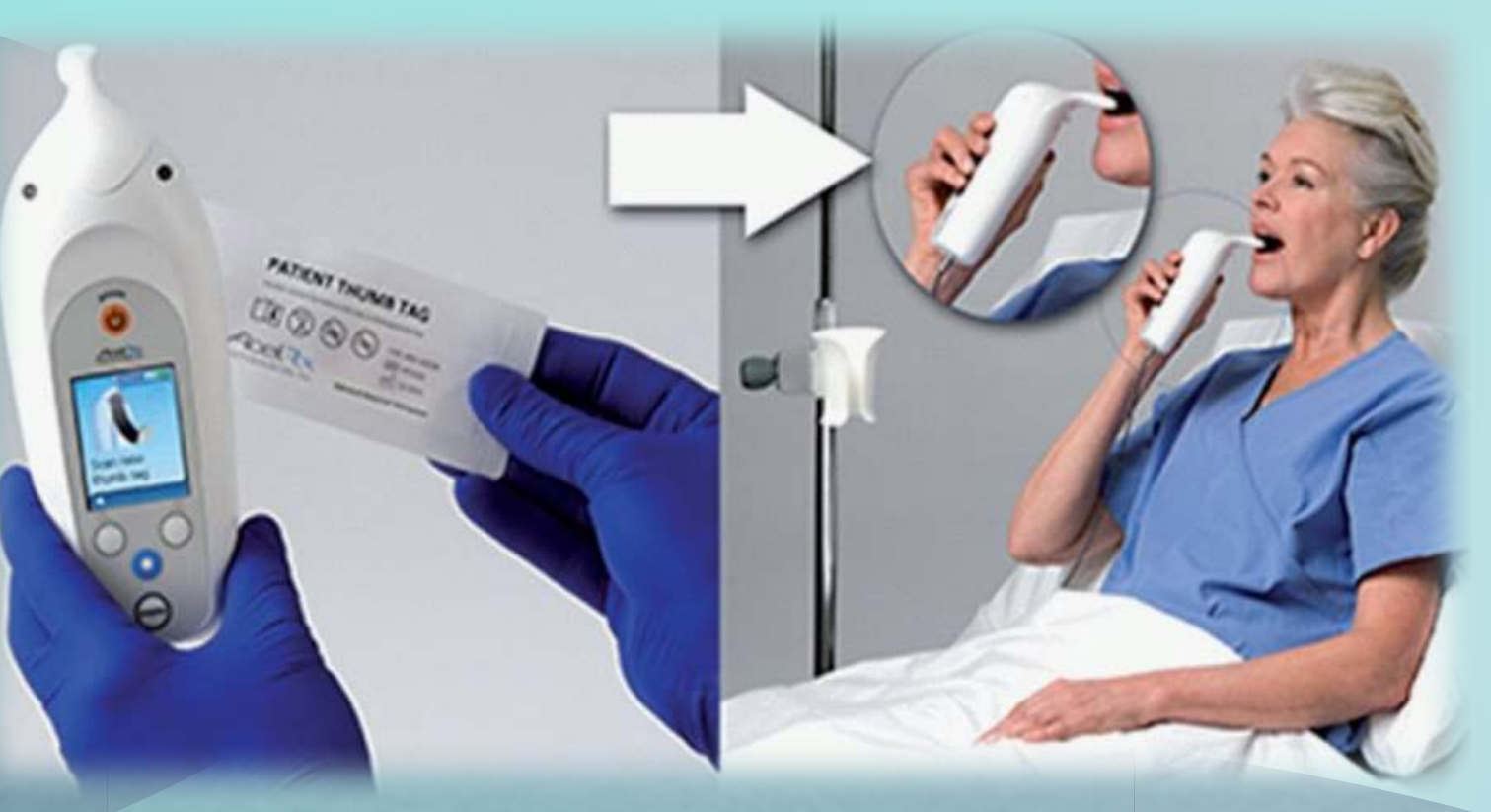

Methods: We enrolled 40 patients (prot.13.17 TS ComEt CBM) to evaluate SSTS efficacy after thoracic surgery. Data collected were: tablets consumption; pain (NRS for the first $72 \mathrm{~h}$ ) at rest and coughing; pre- and post-operative efficacy in incentive spirometer (Triflo).

Results: Mean tablets consumption was 2,46 \pm 0,$84 ; 2,8 I \pm I, 29 ; 3, I I \pm I, 56 ; 3,03 \pm I, 88 ; 3,84 \pm I, 44$; $1,54 \pm 2,16$ respectively after $2,6,12,24,48$ and 72 hours after surgery. Overall consumption was $16,78 \pm 11,79$. Mean total requested and not delivered tablets were 4,4I $\pm 2,5 I$. Mean NRS was 4,56 $\pm 1,91$ / 6,65 $\pm 2,12$ (rest / coughing), before the first dose and $3 \pm 1,3 / 4,54 \pm 1,83 ; 2,08 \pm 1,32$ / $3,78 \pm 1,38 ; 1,81 \pm 1,41 / 3,54 \pm 1,94 ; 1,73 \pm 1,19$ / $3,19 \pm 1,8 ; 0,49 \pm 1,02 / 1,45 \pm 1,74 ; 0,27 \pm 0,84$ / $1,03 \pm 1,48$ respectively after $2,6,12,24,48$ and 72 hours. Mean "Triflo" balls raised preoperatively were $2,9 \pm 0,4$. And postoperatively were $\mathrm{I}, 76 \pm 0,64 ; 2,19 \pm 0,52 ; 2,5 \mathrm{I} \pm 0,6 \mathrm{I}$ respectively after 2; 6; 12 hours. No differences were observed in the subsequent measurements.
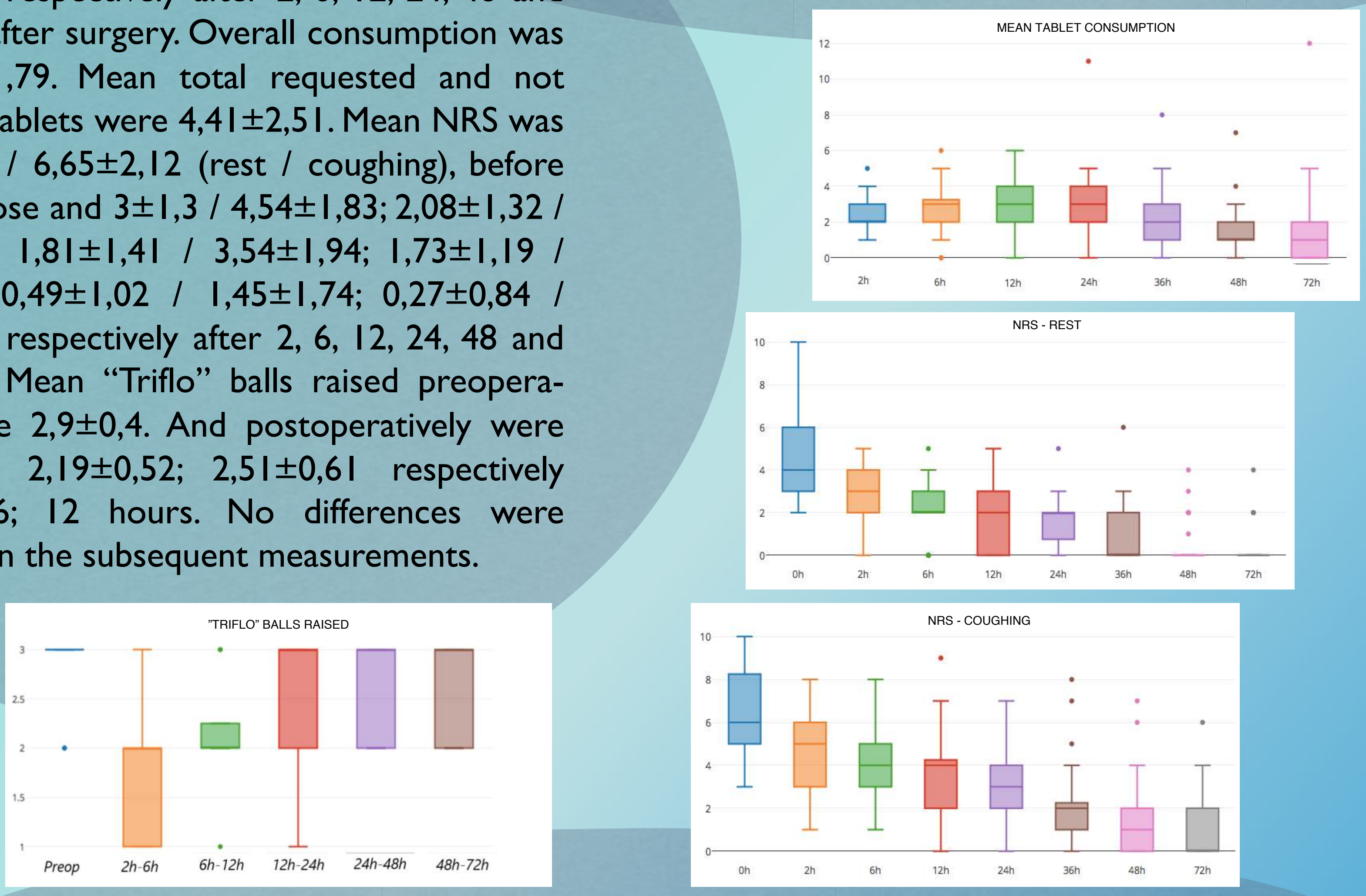

Conclusions: SSTS is a valid alternative to regional techniques for postoperative pain management after thoracic surgery. It is effective at very low doses, and it is not invasive.

I. Nalini Vadivelu, et Al Recent Advances in Postoperative Pain Management Yale J Biol Med. 2010 Mar; 83(I): II-25.

2. Ringold FG et Al Sufentanil sublingual tablet system for the management of postoperative pain following open abdominal surgery: a randomized, placebo-controlled study. Reg Anesth Pain Med. 20I5 Jan-Feb;40(I):22-30.

3. Jove M et Al. Sufentanil Sublingual Tablet System for the Management of Postoperative Pain after Knee or Hip Arthroplasty: A Randomized, Placebo-controlled Study. Anesthesiology. 20I 5 Aug; I23(2):434-43.

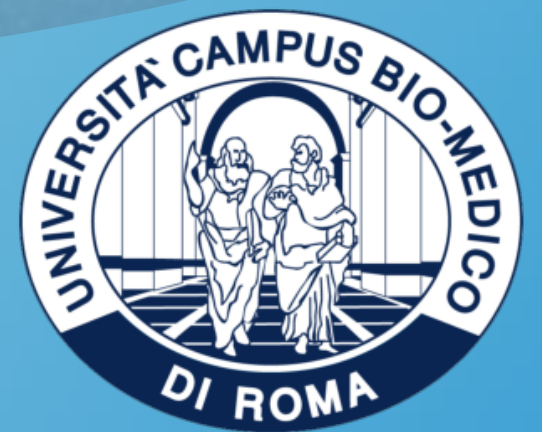

